\title{
HEALTH AND SAFETY PROFESSIONALS' RATING OF MANAGEMENT ATTITUDE AND COMMITMENT ON INJURY RATE AND SEVERITY IN SMALL AND MEDIUM SIZED CONSTRUCTION COMPANIES
}

Katherine Schofield, Bruce Alexander, Susan Gerberich, Andrew Ryan University of Minnesota, Minneapolis, USA

10.1136/oemed-2011-100382.175

Objectives To characterise the impact of health and safety professionals' evaluations of management attitude and commitment to safety on injury rate and severity in construction workers employed by 1360 small and medium construction companies covered under a single workers' compensation insurance carrier.

Methods Hours at-risk ( $\mathrm{N}=185766$ 467), estimated from payroll, and injury claims ( $\mathrm{N}=9986$ total, and 2292 lost time) were used to determine injury rates. Management safety attitude rating was conducted by health and safety professionals in the carrier's internal loss control department. A company would have no rating until this initial visit occurred. Based on a standardised process to characterise the activities, safety measures, hazards of a company, and interactions between the company and loss control representative, an attitude and safety commitment rating was assigned; good, poor/needs improvement, and not yet rated. Rate ratios (RR) and 95\% CI were estimated as a function of injury rate using a time dependent Poisson regression model. Generalised estimating equations were used to account for correlated observations within companies over time. Models include confounding covariates of company size, union status, and trade.

Results Compared to good (N=7688), RRs for poor/needs improvement $(\mathrm{N}=363)$; and not yet rated $(\mathrm{N}=1935)$ were, respectively 0.94 ( $\mathrm{CI}=0.74$ to 1.19$)$ and 1.11 ( $\mathrm{CI}=1.03$ to 1.21$)$ for overall injuries, and 1.15 (CI=0.85 to 1.55$)$ and $1.13(\mathrm{CI}=0.99$ to 1.28) for lost-time injuries.

Conclusions Rating of attitude and commitment from a single visit may not be indicative of injury risk. However, risk of injury was higher in periods prior to the evaluations by the health and safety professional. 